\title{
Polipirol ve Poliakrilonitril / Kil Kompozitlerin Hazırlanması ve Termal Özelliklerinin İncelenmesi
}

\author{
Seyfullah Madakbaş ${ }^{1 *}$, Memet Vezir KAHRAMAN $^{1}$, Ferhat $_{\text {ŞEN }}{ }^{1}$, Kadir ESMER $^{2}$ \\ ${ }^{1}$ Marmara Üniversitesi Fen-Edebiyat Fakültesi Kimya Bölümü, 34722, Kadlköy - İstanbul \\ ${ }^{2}$ Marmara Üniversitesi Fen-Edebiyat Fakültesi Fizik Bölümü, 34722, Kadıköy - İstanbul
}

\section{Özet}

$\mathrm{Bu}$ çalışmada polipirol ve poliakrilonitrilin termal özelliklerinin geliştirilmesi amaçlandı. $\mathrm{Bu}$ amaç için polipirol ve poliakrilonitril / kil kompozitler farklı metotlar ile hazırlandı. Hazırlanan kompozitlerin termal özellikleri termal gravimetrik analiz (TGA) ve diferansiyel taramalı kalorimetri (DSC) teknikleri ile incelendi. Elde edilen sonuçlar kompozit formülasyonlarında kil içeriğinin artması ile kompozitlerin termal özelliklerinde önemli bir artış olduğunu gösterdi.

Anahtar Kelimeler: İletken polimerler, polipirol, poliakrilonitril, kil, kompozitler, termal özellikler

\section{Preparation and Investigation of Thermal Properties of Polypyrrole and Polyacrylonitrile / Clay Composites}

\begin{abstract}
The aim of this study was to improve thermal properties of polypyrrole and polyacrylonitrile. For this purpose, polypyrrole and polyacrylonitrile / clay composites were prepared by different methods. The thermal properties of the prepared composites were examined by thermal gravimetric analysis (TGA) and differential scanning calorimetry (DSC) techniques. The results obtained showed that thermal properties of the composites were a significantly increased with the increase in clay content in the formulation of composite.
\end{abstract}

Keywords: Conductive polymers, polypyrrole, polyacrylonitrile, clay, composites, thermal properties 


\section{Giriş}

İletken polimerler üstün elektriksel, optik ve kimyasal yapılarından dolayı sensör kullanımında, şarj olabilen pil yapımında, iyon seçici elektrotlarda, elektronik aletlerde, fotokimyasal hücrelerde, iletken lif yapımında ve korozyon önleyici olarak sıklıkla kullanılmaktadır [1-2]. Bir çeşit iletken polimer olan polipirol yüksek iletkenlik özelliğinin yanı sıra oksijen ve havaya karşı üstün çevresel kararlılığa sahiptir. Bu özelliklerinden dolayı polipirol sensörler, 1ş1k yayan diyotlar, organik alan etkili transistörler, elektromanyetik parazit koruyucu, pil, kapasitör gibi elektronik uygulamalar için önde gelen bir materyaldir [3]. Poliakrilonitril ise sentetik lif üretiminde yaygın olarak kullanılan önemli bir mühendislik polimer materyalidir. Bunun yanında güçlü bir statik elektriğe sahip olduğundan dolayı toz ve mikropları kolay bir şekilde absorblamaktadırlar [4]. Bu derece yaygın olarak kullanılan polipirol ve poliakrilonitrilin termal özelliklerinin geliştirilmesi gerekmektedir. Bu sebeple bu çalışmada polipirol ve poliakrilonitrilin termal özelliklerinin geliştirilmesi amaçlandı. $\mathrm{Bu}$ amaç için polipirol ve poliakrilonitril / kil kompozitler farklı metotlar ile hazırlandı. Hazırlanan kompozitlerin termal özellikleri termal gravimetrik analiz (TGA) ve diferansiyel taramalı kalorimetri (DSC) teknikleri ile incelendi.

\section{Materyal ve Yöntem}

\section{Kullanilan Kimyasallar}

Pirol monomeri ve poliakrilonitril Sigma-Aldrich'den (ABD) satın alındı ve hiçbir işlem yapılmadan kullanıldı. Yükseltgeme ajanı olarak kullanılan $\mathrm{FeCl}_{3} .6 \mathrm{H}_{2} \mathrm{O}$ Merck'den (Almanya) satın alındı. Yüzey aktif madde olarak kullanılan dodesilbenzen sülfonik asit ve çözücü olarak kullanılan metanol ve dimetilformamit Fluka'dan (İsviçre) satın alındı. Kil doğal ham madde olarak Enez'den (Edirne, Türkiye) elde edildi. Kullanılan kilin kimyasal yapıs1 atomik absorbsiyon spektroskopisi tekniği ile \%62.80 $\mathrm{SiO}_{2}, \% 19.00 \mathrm{Al}_{2} \mathrm{O}_{3}, \% 2.20$ $\mathrm{Fe}_{2} \mathrm{O}_{3}, \% 4.60 \mathrm{CaO}, \% 1.80 \mathrm{MgO}, \% 1.00 \mathrm{Na}_{2} \mathrm{O}, \% 0.76 \mathrm{~K}_{2} \mathrm{O}, \% 0.75 \mathrm{TiO}_{2}$ ve $\% 7.39$ yanma kaybı olarak belirlendi (Esmer ve Tarcan, 2001).

\section{Deneysel Yöntemler}

Polipirol Peighambardoust ve Pourabbas tarafindan 2007 yılında bildirilen bir yönteme göre sentezlendi. $0.15 \mathrm{~mol}$ dodesilbenzen sülfonik asit, $0.30 \mathrm{~mol}$ pirol monomeri ve $400 \mathrm{~mL}$ distile su oda sıcaklığında karıştırıldı. Daha sonra $100 \mathrm{~mL}$ saf su içerisinde çözülen $0.06 \mathrm{~mol}$ $\mathrm{FeCl}_{3} 6 \mathrm{H}_{2} \mathrm{O}$ monomer - yüzey aktif madde karışımına eklendi. Reaksiyon 5 saat oda sıcaklığında karıştırıldı. Elde edilen çökelti vakumda süzüldü, sırasıyla saf su ve methanol ile yıkand1. $50{ }^{\circ} \mathrm{C}$ 'de vakum altında kurutulduktan sonra siyah polipirol tozu elde edildi. $\% 5$, $\% 10$ ve \%15 oranlarında kil içeren polipirol / kil kompozitler hazırlamak için ilk olarak hesaplanan kil miktarı $400 \mathrm{~mL}$ saf su içerisinde disperse edildi. Dodesilbenzen sülfonik asit ve pirol monomeri hazırlanan kil süspansiyonu içerisine eklendi. Oksidasyon aracı karışıma eklenerek yukarıda anlatıldı̆̆ şekilde saflaştırma işleminin ardından polipirol / kil kompozitler elde edildi [5-6].

$1 \mathrm{~g}$ poliakrilonitril $15 \mathrm{~mL}$ dimetilformamit içerisinde çözüldü ve $\% 5, \% 10, \% 15$ ve $\% 20$ oranlarında kil ilave edilerek $80^{\circ} \mathrm{C}$ 'de 6 saat karıştırıldı. Elde edilen çökelti süzülüp $40^{\circ} \mathrm{C}^{\prime} \mathrm{de}$ vakum altında kurutularak poliakrilonitril / kil kompozitler elde edildi [7]. 


\section{Kompozitlere Uygulanan Test Yöntemleri}

Hazırlanan kompozitlerin termo-oksidatif kararlılıklarını ölçmek amacıyla Perkin Elmer Pyris 1 model TGA cihazı kullanıldı. Analiz $30{ }^{\circ} \mathrm{C}$ 'den $750{ }^{\circ} \mathrm{C}$ 'ye $10{ }^{\circ} \mathrm{C} /$ dakika hizla hava atmosferi altında isıtılarak yapıldı. Kompozit filmlerin termal kararlılıklarını değerlendirmek için $\% 10$ ve maksimum kütle kaybının meydana geldiği sıcaklıklar ile $750{ }^{\circ} \mathrm{C}$ 'de geriye kalan $\%$ kül miktarı dikkate alındı.

Hazırlanan kompozitlerin camsı geçiş sıcaklıklarını belirlemek için Pyris Diamond DSC cihazı kullanıldı. Hazırlanan kompozitlerden 8-10 mg arasında numuneler alınıp, $30{ }^{\circ} \mathrm{C}$ 'den $300{ }^{\circ} \mathrm{C}$ 'ye kadar $10{ }^{\circ} \mathrm{C} /$ dakika hızı ile 1sitılıp, $300{ }^{\circ} \mathrm{C}$ 'de $5 \mathrm{dk}$ boyunca tutulmuş, bu sicaklıktan $0{ }^{\circ} \mathrm{C}$ 'ye kadar $50{ }^{\circ} \mathrm{C} /$ dakika hız ile soğutulmuş, $0{ }^{\circ} \mathrm{C}$ 'de $5 \mathrm{dk}$ boyunca tutulmuş ve tekrar $0{ }^{\circ} \mathrm{C}$ 'den $300{ }^{\circ} \mathrm{C}$ 'ye kadar $10^{\circ} \mathrm{C} /$ dakika hız ile isitılmıştır. Deney sirasında ortama $20 \mathrm{mg} /$ dakika hız ile azot gazı verilmiştir.

\section{Bulgular ve Tartışma}

Polipirol / Kil Kompozitlere uygulanan TGA analizi sonucunda elde edilen termogramlar Şekil 1.'de gösterilmiştir. Termogramlardan elde edilen veriler ise Tablo 1.'de listelenmiştir. Kompozitlerin \%5'lik kütle kayıplarının $180{ }^{\circ} \mathrm{C}$ civarında, maksimum kütle kayıplarının 300 ${ }^{\circ} \mathrm{C}$ civarında ve $750{ }^{\circ} \mathrm{C}$ 'deki kül miktarlarının \%23-34 aralığında olduğu tespit edilmiştir.

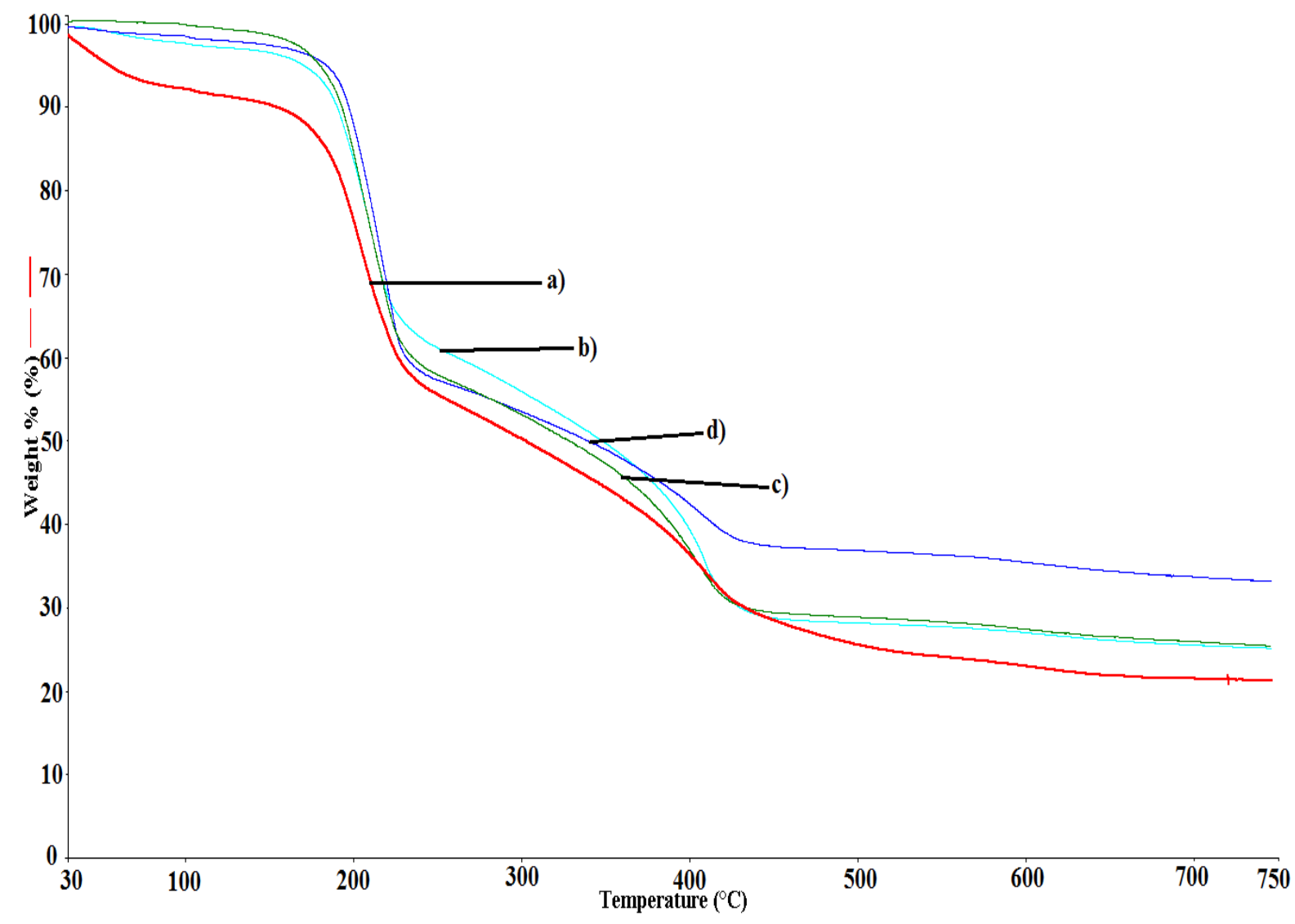

Şekil 1. Polipirol / Kil Kompozitlerin Termogramları a) Saf Polipirol, b) \%5 Kil, c) \%10 Kil, d) $\% 15 \mathrm{Kil}$ 
Tablo 1. Polipirol / Kil Kompozitlerin Termal Özellikleri

\begin{tabular}{ccccc}
\hline Numune & $\begin{array}{c}\text { \%10 Kütle Kaybının } \\
\text { Meyd. Geld. Sıc. }\left({ }^{\circ} \mathbf{C}\right)\end{array}$ & $\begin{array}{c}\text { Mak. Küitle Kaybının } \\
\text { Meyd. Geld. Sic. }\left({ }^{\circ} \mathbf{C}\right)\end{array}$ & \% Kül & Tg $\left({ }^{\circ} \mathbf{C}\right)$ \\
\hline Saf Polipirol & 171 & 274 & 23 & 109 \\
Polipirol / \%5 Kil & 180 & 307 & 25 & 111 \\
Polipirol / \% 10 Kil & 189 & 329 & 26 & 115 \\
Polipirol / \%15 Kil & 198 & & 34 & 120 \\
\hline
\end{tabular}

Poliakrilonitril / Kil Kompozitlere uygulanan TGA analizi sonucunda elde edilen termogramlar Şekil 2.'de gösterilmiştir. Termogramlardan elde edilen veriler ise Tablo 2.'de listelenmiştir. Kompozitlerin \%5'lik kütle kayıplarının $320{ }^{\circ} \mathrm{C}$ civarında, maksimum kütle kayıplarının $600{ }^{\circ} \mathrm{C}$ civarında ve $750{ }^{\circ} \mathrm{C}$ 'deki kül miktarlarının \%0-51.4 aralığında olduğu tespit edilmiştir.

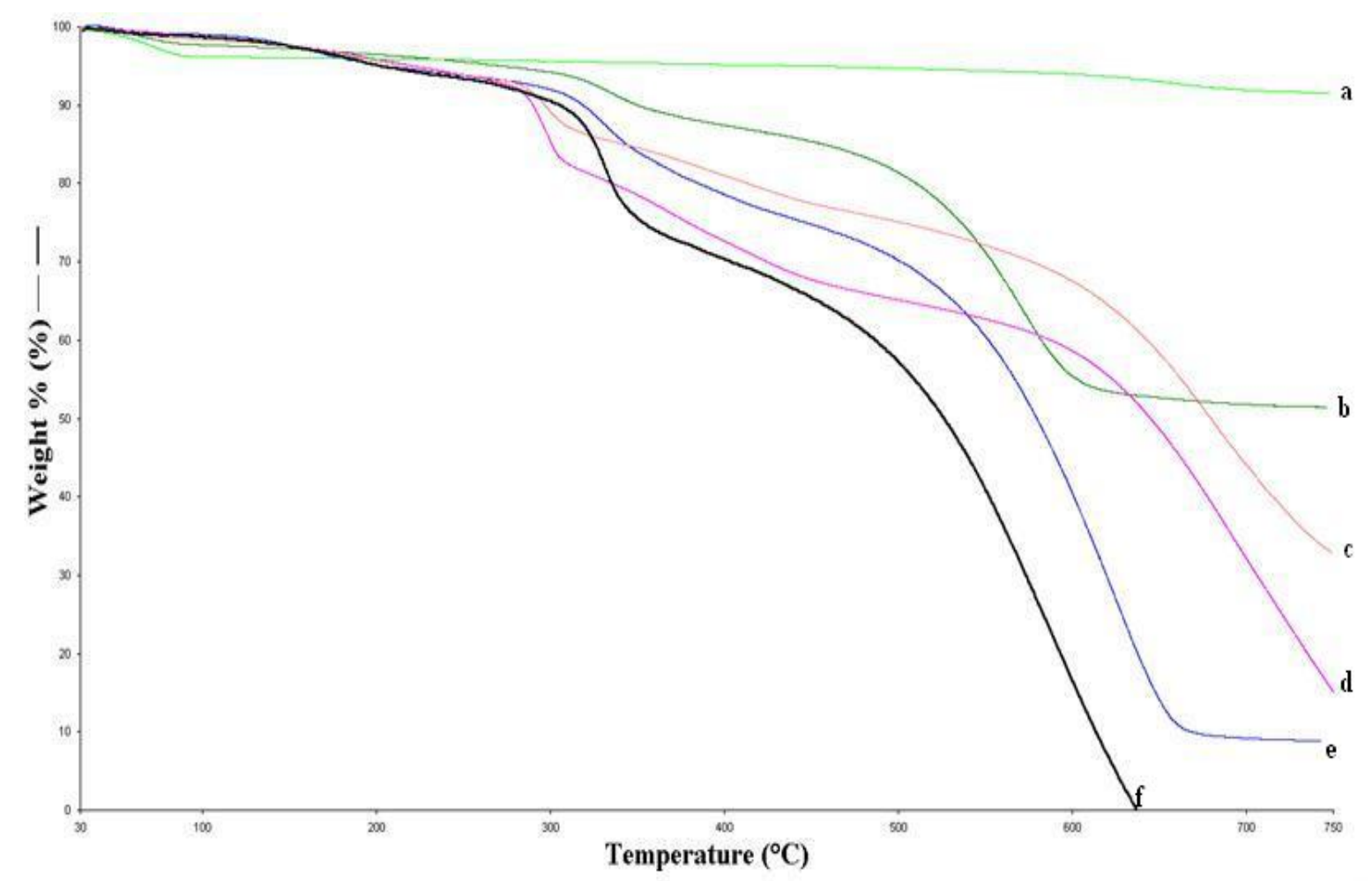

Şekil 2. Poliakrilonitril / Kil Kompozitlerin Termogramları a) Saf Kil, b) \%20 Kil, c) \%15 Kil, d) \%10 Kil, e) \%5 Kil, f) Saf Poliakrilonitril 
Tablo 2. Poliakrilonitril / Kil Kompozitlerin Termal Özellikleri

\begin{tabular}{lcccc}
\hline \multicolumn{1}{c}{ Numune } & $\begin{array}{c}\text { \%10 Kütle } \\
\text { Kaybının Meyd. } \\
\text { Geld. Sıc. }\left({ }^{\circ} \mathbf{C}\right)\end{array}$ & $\begin{array}{c}\text { Mak. Kütle } \\
\text { Kaybının Meyd. } \\
\text { Geld. Sı. }\left({ }^{\circ} \mathbf{C}\right)\end{array}$ & \% Kül & Tg $\left({ }^{\circ} \mathbf{C}\right)$ \\
\hline Saf Poliakrilonitril & 303 & 521 & 0,0 & 85 \\
Poliakrilonitril / \%5 Kil & 309 & 572 & 9,3 & 48 \\
Poliakrilonitril / \% 10 Kil & 310 & 642 & 15,1 & 61 \\
Poliakrilonitril / \% 15 Kil & 296 & 680 & 33,0 & 88 \\
Poliakrilonitril / \% 20 Kil & 347 & 681 & 51,4 & 116 \\
\hline
\end{tabular}

Tüm sonuçlar değerlendirildiğinde kompozitler içerisindeki kil içeriğinin artması ile \%5'lik kütle kayıplarının ve maksimum kütle kayıplarının meydana geldiği sıcaklıklarda bir artış olduğu görülmektedir. Bu artış kil katkısının ısıl parçalanma için gerekli aktivasyon enerji seviyesini yükselterek termal kararlılığı arttırdığını göstermektedir. Diğer yandan kompozitler içerisindeki kil içeriğinin artması ile kompozitlerin kül miktarında önemli ölçüde artış olduğu görülmektedir. Kül oluşumu; alev direnci için çok önemli olup altında bulunan polimeri yalıtmakta, alevin beslenmesini ve içeriye hava girişini engellemektedir [8].

Kompozitlerin DSC analizi sonucunda elde edilen camsı geçiş sıcaklıkları Tablo 1. ve Tablo 2.'de listelenmiştir. Elde edilen sonuçlar tüm kompozitlerde kil içeriğinin artması ile $T_{g}$ değerlerinde bir artış olduğunu göstermektedir. $\mathrm{Bu}$ durum kompozit filmin serbest hacmindeki azalma nedeniyle polimer zincirinin hareketliliğinin kısıtlanmasından kaynaklanmaktadır [9].

\section{Sonuç}

$\mathrm{Bu}$ çalışmada ilk olarak polipirol başarılı bir şekilde sentezlendi, Polipirol / Kil ve Poliakrilonitril / Kil kompozitler hazırlandı. Hazırlanan kompozitlerin termal özelliklerini belirlemek amacıyla TGA ve DSC analizleri yapıldı. Elde edilen sonuçlar kompozit formülasyonlarında kil içeriğinin artması ile kompozitlerin termal özelliklerinde önemli bir artış olduğunu gösterdi. 


\section{Teşekkür}

Bu çalışma FEN-D-220513-0217 numaralı proje kapsamında Marmara Üniversitesi Bilimsel Araştırma Projeleri Koordinasyon Birimi (BAPKO) tarafından desteklenmiştir.

\section{Kaynaklar}

[1] Goh, S.H., Chan, H.S.O. ve Ong, C.H. (1998). Miscible blends of conductive polyaniline with tertiary amide polymers. J. Appl. Polym. Sci., 68, 1839-1844.

[2] Chen, K.H. ve Yang, S.M. (2003). Polyaniline-montmorillonite composite synthesized by electrochemical method. Synth. Met., 135, 151-152.

[3] Omastova, M. ve Micusik, M. (2012). Polypyrrole coating of inorganic and organic materials by chemical oxidative polymerisation. Chem. Pap., 66, 392-414.

[4] Chang, L.T. ve Yen, C.C. (1995). Studies on the preparation and properties of conductive polymers. VIII. Use of heat treatment to prepare metallized films from silver chelate of PVA and PAN. J. Appl. Polym. Sci., 55, 371-374.

[5] Madakbaş, S., Çakmakçı, E., Kahraman, M.V. ve Esmer, K. (2013). Preparation, characterisation, and dielectric properties of polypyrrole-clay composites. Chem. Pap., 67, 1048-1053.

[6] Shirakawa, H., Louis, E.J., MacDiarmid, A.G., Chiang, C.K. ve Heeger, A.J. (1977). Synthesis of electrically conducting organic polymers: halogen derivatives of polyacetylene, $(\mathrm{CH})_{\mathrm{x}}$. J. Chem. Soc. Chem. Com., 16, 578-580.

[7] Pant, H.C., Patra, M.K., Negi, S.C., Bhatia, A., Vadera, S.R. ve Kumar, N. (2006). Studies on conductivity and dielectric properties of polyaniline-zinc sulphide composites. Bull. Mater. Sci. 29, 379-384.

[8] Madakbaş, S., Çakmakçı, E., Kahraman, M.V. (2013). Preparation and thermal properties of polyacrylonitrile/hexagonal boron nitride composites. Thermochim. Acta, 552, 1-4.

[9] Şen, F. Ve Kahraman, M.V. (2013). Preparation and Properties of Nano Diamond / 6FBisphenol A Based Cyanate Ester Composites. Polym. Composite., 34, 1977-1985. 